\title{
Anesthesia in Yemen: Working with Médecins Sans Frontières
}

\author{
Gordon Wood, MD
}

Received: 7 July 2017/Revised: 25 July 2017/Accepted: 10 August 2017/Published online: 17 August 2017

(c) Canadian Anesthesiologists' Society 2017

\section{To the Editor,}

Canadian anesthesiologists may not be aware of the numerous opportunities available to participate in anesthesia outreach projects in under-resourced countries around the world. Several humanitarian organizations, including Doctors Without Borders/Médecins Sans Frontières (MSF), the Canadian Anesthesiologists' Society International Education Foundation (CASIEF), and the Red Cross require anesthesiologists for short assignments (four to eight weeks), allowing physicians to maintain their employment in Canada and still make significant contributions overseas. I have volunteered with several organizations, including CASIEF and Operation Smile and have recently taken time off from my job as an anesthesiologist and intensivist in Victoria, British Columbia to work with MSF in the Middle East.

Médecins Sans Frontières is an independent medical organization that delivers emergency medical and humanitarian relief in many countries worldwide. Some of the projects are in areas of armed conflict, where MSF operates trauma surgery hospitals. I was in Iraq in 2016 and have recently returned from a six-week assignment with MSF in the city of Aden in southern Yemen, where I worked in an emergency surgical hospital.

Yemen is a country of 26 million people in the midst of a complex civil war that has resulted in a widespread humanitarian crisis. ${ }^{1}$ The government hospitals in Aden are either closed or are operating at a very reduced capacity. The disintegration of the local economy has left most people unable to pay for services in the city's private hospitals. The MSF surgical hospital provides care free of

G. Wood, MD ( $\square)$

Vancouver Island Health Authority, Victoria, BC, Canada

e-mail: gordon.wood@viha.ca charge for victims of trauma in a city offering few alternatives.

The hospital is financed and managed by MSF. The doctors and nurses are Yemenis who have been trained locally and mentored by expatriate MSF surgeons and anesthesiologists. There are three operating rooms in the hospital, 75 inpatient beds, and an eight-bed intensive care unit (ICU). As the expatriate anesthesiologist, my responsibilities included going on rounds daily with the surgical staff to see the 75 inpatients, provide patient care in the ICU, and mentor local physicians and anesthesiologists working in the ICU and operating rooms. The local physicians have accumulated a vast amount of experience managing penetrating trauma. A disproportionate number of trauma patients presented in the evenings, when I spent much of my time administering anesthesia for damage-control surgery and stabilizing seriously injured patients in the ICU.

Although the front line of the civil war has moved three hours north of Aden, the number of patients presenting to the emergency room with penetrating injuries and blast trauma continues to increase. Landmines and unexploded ordinances left behind from previous fighting, a heavily armed civilian population, a breakdown of civil authority, and disruption of the social order foster violence in the absence of active combat. Despite this situation, the hospital remains a secure facility within a walled compound. It is well equipped, and there is no shortage of essential anesthetic drugs. There is a blood bank that supplies stored red blood cells and fresh frozen plasma as well as fresh blood donated by the families of injured patients. Recently a microbiology laboratory has opened.

I encourage interested anesthesiologists to consider working with MSF or other humanitarian organizations to assist in delivering lifesaving healthcare for people who 
have limited access to safe anesthesia and surgery. In addition, the opportunity to educate local physicians leads to sustainable improvement in the quality of medical care in these countries. This work advances Canada's crucial role in medical outreach endeavors. Médecins Sans Frontières Canada is currently recruiting anesthesiologists for one- to six-month rotations in surgical projects in many countries. $^{2}$

Conflicts of interest None declared.

Editorial responsibility This submission was handled by Dr. Gregory L. Bryson, Deputy Editor-in-Chief, Canadian Journal of Anesthesia.

\section{References}

1. United Nations Office for the Coordination of Humanitarian Affairs. Yemen: Crisis Overview. Available from URL: http:// unocha.org/yemen/crisis-overview (accessed August 2017).

2. Médecins Sans Frontières. Work with us - Anaesthesiologists. Available from URL: http://www.msf.ca/en/anaesthesiologists (accessed August 2017). 